\title{
In Cranial Nerves Palsy, Do not Miss Fungal Etiology
}

Attia $\mathrm{TH}^{1 *}$ and Saeed $\mathrm{MA}^{2}$

${ }^{1}$ Pediatric Department, Zagazig University, Egypt

${ }^{2}$ Tropical Medicine Department, Zagazig University, Egypt

*Corresponding author: Attia TH, Pediatric Department, Zagazig University, Egypt, Tel: +00201276099800; E-mail: tareqhamed@live.com

Received date: November 30, 2015; Accepted date: December 02, 2015; Published date: December 04, 2015

Copyright: (c) 2015 Attia TH, et al. This is an open-access article distributed under the terms of the Creative Commons Attribution License, which permits unrestricted use, distribution, and reproduction in any medium, provided the original author and source are credited.

Keywords: Cranial nerves; Cerebral mucormycosis

\section{Case and Discussion}

Mucormycosis is a rare opportunistic fungal infection caused by filamentous fungi of order Mucorale. It is characterized by infection and necrosis of host tissue that is resulted from invasion of vasculature by hyphae. The genera most commonly found in human infection is Rhizopus and Mucor [1]. Based on its clinical presentation and anatomic sites invasive mucormycosis is classified into 6 clinical forms: rhino-cerebral, pulmonary, cutaneous, gastro-intestinal, disseminated and uncommon rare form such as endocarditis, peritonitis and renal infection [2]. The most important risk factors predisposing to mucormycosis include malignant hematological diseases, prolonged and sever neutropenia, poorly controlled diabetes mellitus with or without ketoacidosis, major trauma, prolonged use of corticosteroid and malnutrition $[1,3]$ (Figure 1).

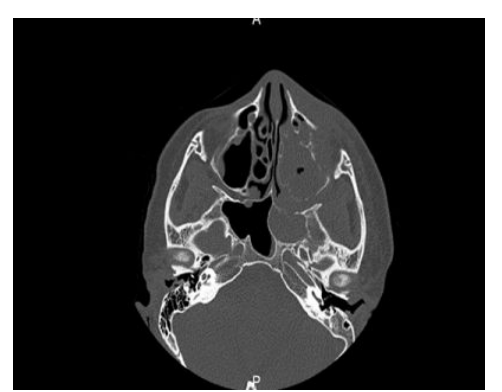

Figure 1: Axial CT of the paranasal sinuses showed extensive mucosal thickening of the left maxillary antrum, sphenoidal sinus and left ethmoidal air cells.

In most cases the infection is rapidly progressive and results in death unless underlying risk factors are corrected and aggressive treatment, with antifungal agents and surgical excision, is initiated [3]. Rhinocerebral mucormycosis (RCM) is the most common and fatal clinical form of mucormycosis which presumed to start with inhalation of spores into paranasal sinuses of susceptible host [1]. Dental care may also precede such an infection by creating a post extraction wound which may be susceptible to fungal infection as seen in our case [4]. Hyperglycemia, usually with an associated metabolic acidosis, is the most common underlying condition [1]. Rhizopus organisms have an enzyme, ketone reductase, which allow them to thrive in high glucose levels, at the same time hyperglycemia may alter the immunologic capability to resist mucormycosis through reduction of leucocytes chemotaxis [5].
We present a case of RCM in a 14 years-old diabetic girl who presented with a 2 weeks history of left facial and periorbital swelling associated with left facial numbness and hypoesthesia in the area supplied by ophthalmic, maxillary and mandibular branches of the fifth cranial nerve (Figure 2).

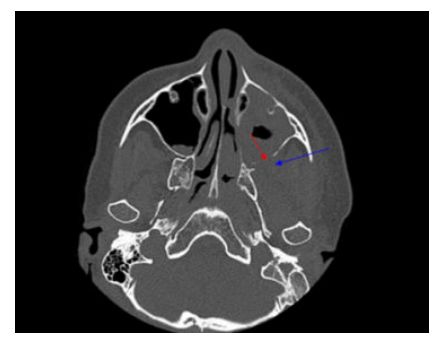

Figure 2: Axial CT scan of the paranasal sinuses showed circumferential mucosal thickening of the left maxillary antrum with destruction of the posterior wall of the antrum (red arrow) and retro-antral extension (blue arrow).

Also there was left facial palsy. The hall marks of spread of infection beyond the sinuses are tissue necrosis of the palate resulting in palatal eschar, facial swelling, erythema and cyanosis of the facial skin overlying the involved sinuses [6]. Signs of orbital involvement include periorbital edema, proptosis and blindness. Facial numbness is frequent and results from infarction of sensory branches of the fifth cranial nerve [7]. Our patient had left facial numbness and hypoesthesia in the area supplied by ophthalmic, maxillary and mandibular branches of the fifth cranial nerve (Figure 3).

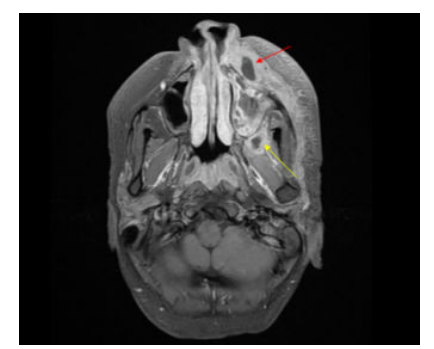

Figure 3: Axial MRI T1 fat saturation post contrast showed mucosal thickening of all left paranasal sinuses. Also it revealed thickened enhanced wall abscess in the left pre maxillary soft tissue (red arrow), retro antral region (yellow arrow) and left orbital floor. 
Citation: Attia TH, Saeed MA (2016) In Cranial Nerves Palsy, Do not Miss Fungal Etiology. J Neurol Disord 4: i003. doi:

Page 2 of 2

Computed tomography (CT) revealed mucosal thickening of all left paranasal sinuses as well as destruction of the posterior wall of the antrum and retro-antral extension.

Further imaging with magnetic resonance imaging (MRI) also showed involvement of all left paranasal sinuses with retro-orbital extension and there was abscess formation in the anterior maxillary area and left orbital floor (Figure 3) as well as mucosal thickening of the left maxillary antrum with areas of low signal intensity (Figure 4).

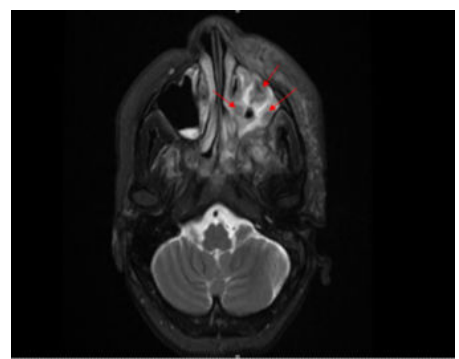

Figure 4: Axial MRI T2 showed mucosal thickening of the left maxillary antrum with areas of low signal intensity (red arrows).

There was no involvement of central nervous system. Based on the history, clinical presentation and imaging findings a provisional diagnosis of RCM was considered. Fungal cultures confirmed the clinical diagnosis (Figures 5 and 6).

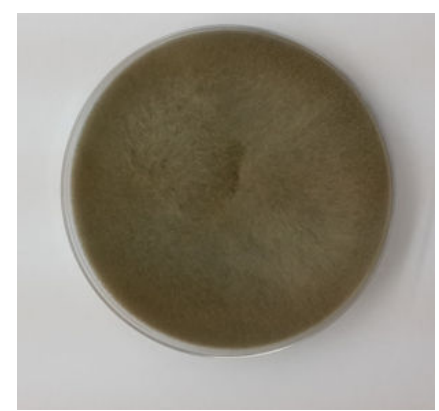

Figure 5: Zygomycete culture growing on bread.

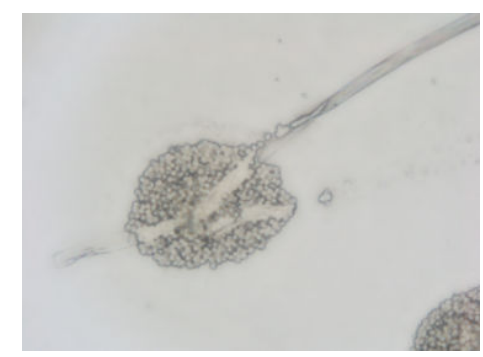

Figure 6: Unbranched Sporangiophores with big sporangia.
Treatment of RCM is based on reversal of underlying predisposing factor, prompt initiation of antifungal therapy and surgical debridement of involved tissues [3]. However there was no any recommendation in the literature on the duration of antifungal, extent and timing of appropriate surgical management. Our case was successfully treated with antifungal liposomal amphotericin B and posaconazole, as step-down therapy for 8 months, and minimal surgical debridement.

\section{Conclusion}

Mucormycosis should be considered in a predisposed patient who presented with cranial nerves deficits. Although extensive surgical debridement could not be performed, disease regression could be achieved with medical therapy and minimal debridement. We present this case because of the rarity of RCM, calling for prompt initiation of treatment in a suspected case and to present data about therapeutic modality.

\section{References}

1. Roden MM, Zaoutis TE, Buchanan WL, Knudsen TA, Sarkisova TA, et al (2005) Epidemiology and outcome of mucormycosis: a review of 929 reported cases. Clin Inf Dis 41: 634-653.

2. Galetta SL,Wulc AE, Goldberg HI, Nichols CW, Galser JS (1990) Rhinocerebral mucormycosis : management and survival after carotid occlusion. Ann Neurol 28: 103-107.

3. Spellberg B, Edwards J Jr, Ibrahim A (2005) Novel prospective on mucormycosis: pathophysiology, presentation and management. Clin Microbiol Rev 18: 556-569.

4. Kim J, Fortson J, Cook H (2001) A fatal outcome from rhinocerebral mucormycosis after dental extraction: a case report. J Oral Maxillofac Surg 59: 693-697.

5. Gale GR, Welch AM (1961) Studies of opportunistic fungi. Inhibition of Rhizopus oryzae by human serum. Am J Med Sci 241: 604-612.

6. Rajagopalan S (2005) Serious infection in elderly patients with diabetes mellitus. Clin Inf Dis 40: 990-996.

7. Yohai RA, Bullock JD, Aziz AA, Markert RJ (1994) Survival factors in rhino-orbital-cerebral mucormycosis. Surv Ophthalmo 39: 3-22. 